\title{
REPRESENTACIÓN LEGAL DE LOS TRABAJADORES EN LA EMPRESA Y DISFUNCIONES DERIVADAS DE UN MODELO PLURALISTA EN ESTE ÁMBITO'
} Employee representation in the company and dysfunctions

\author{
derived from pluralistic model \\ Patricia Nieto Rojas*
}

Universidad Carlos III, España

\section{RESUMEN}

El legislador laboral tempranamente asumió la necesidad de articular mecanismos de representación legal de los trabajadores en la empresa, encomendando esta función a dos tipos de sujetos que, por su propia naturaleza, actúan de forma superpuesta a cada trabajador y oponen lo colectivo a lo individual: la representación unitaria y la representación sindical. Ahora bien, hubo que esperar hasta la promulgación de la LOLS para determinar qué secciones podrían asumir la representación de toda la plantilla, pues como es sabido esta función solo se reconoce a las secciones sindicales que cuenten con la mayoría de los delegados de personal o miembros de comités de empresa, generando, con esta decisión legal, una evidente trabazón entre órganos unitarios y sindicales. Partiendo de estas premisas, el presente artículo analiza la doble faz que presenta la representación sindical en la empresa: de un lado, la representación de los intereses específicos de los afiliados sin superar con ello la lógica asociativa; de otro, refiriendo su actividad al conjunto de la colectividad de trabajadores, lo que sitúa la representación ejercida en el plano de la "representación institucional de intereses», extendiendo sus efectos a la totalidad de la plantilla.

Palabras clave: sección sindical; representación legal; comités de empresa; Ley Orgánica Libertad Sindical
\end{abstract}

\section{ABSTRACT}

The legislator early assumed the need to articulate mechanisms for legal representation of workers. Workplace representation in Spain has a clear legal framework, provided in the main by the 1980 workers statute and the 1985 law on trade union freedom Spanish trade unions (articles 8 and 10) also have separate legally recognized structures within the workplace with a range of legal rights. These trade union sections bring together all the members of a particular union in the workplace and some of them can assume the legal representation in the Company. For that, trade unions sections must obtain the majority of the delegates of personnel or members of company committees, generating, with this decision, a clear locking between unitary and trade union bodies. This article analyses the double face presented by trade union representation in the company: On the one hand, the representation of "particular scope" in protecting the specific interests of the affiliates without exceeding the associative logic. Of another, referring to its activity to the whole of the collective of workers, which situates the representation exerted in the plane of the "institutional representation of interests", extending its effects to the whole of the workforce.

Keywords: Trade unions section, workplace representation, work council

1 Ponencia presentada en el IV Encuentro de Profesionales del Asesoramiento Laboral y Social, celebrado en la Facultad de Relaciones Laborales y Trabajo Social (UPV/EHU-Leioa) los días 11 y 12 de abril de 2019.

* Correspondencia a: Patricia Nieto Rojas. Universidad Carlos III, Dpto. Derecho Social, c/Madrid 126, 28903-Getafe, Madrid, España - pnieto@der-pr.uc3m.es - https://orcid.org/0000-0003-3734-3392

Cómo citar: Nieto Rojas, Patricia. (2019). «Representación legal de los trabajadores en la empresa y disfunciones derivadas de un modelo pluralista en este ámbiton; Lan Harremanak, 41, 188-214. (https://doi.org/10.1387/lan-harremanak.20808).

Recibido: 30 abril, 2019; aceptado: 21 junio, 2019.

ISSN 1575-7048 - eISSN 2444-5819 / (C) 2019 UPV/EHU 


\section{SUMARIO}

1. A modo de introducción: un modelo de representación pluralista en la empresa.-2. La representación ejercida por las instancias descentralizadas del sindicato en el ámbito empresarial. 2.1. El elemento constitutivo: la decisión libremente adoptada por trabajadores vinculados por una común afiliación. 2.2. El establecimiento de criterios selectivos para la asunción de esta función. Una decisión legal.-3. La prioridad de la interlocución sindical: una opción de política legislativa.-4. La libertad de auto-organización como fundamento de la elección del ámbito de los órganos representativos de base sindical. 4.1. Las secciones sindicales de afectación a la totalidad de la empresa. 4.2. Propuestas de reforma: hacia una mayor sindicalización de la representación unitaria en la empresa.—5. Bibliografía citada

\section{A modo de introducción: un modelo de representación pluralista en la empresa}

El modelo legal de representación en la empresa se sustenta en la coexistencia de diversas instancias, algunas con competencias generales, otras solo con competencias específicas, unidas por estrechos vínculos, de naturaleza orgánica y funcional (Nieto Rojas, 2016). Esta pluralidad subjetiva hace muy complejo el modelo legal, pues en un ámbito tan reducido como el empresarial coexisten un amplio abanico de sujetos representativos, debiendo sistematizarlos a partir de la siguiente clasificación: De un lado, la representación de alcance general u omnicomprensiva con la que se hace referencia a la actuación representada que pueden asumir las instancias de base electiva (comités de empresa o delegados de personal en la regulación dada por el Título II del ET) o sindicales con representatividad probada en la empresa (esto es, secciones y delegados sindicales conforme a lo dispuesto en la LOLS). Tanto las instancias unitarias como las secciones sindicales con representatividad probada asumen en la empresa la defensa de intereses colectivos, de carácter profesional, que se sobreponen a los intereses particulares de los representados. De otro, la representación de los afiliados que las instancias sindicales de empresa pueden asumir, pues por su propia configuración normativa, tanto secciones como delegados pueden representar los intereses particulares de sus afiliados; representación que, en el presente artículo, hemos calificado como "representación con un alcance particular», pues la misma adquiere un marcado carácter privatista. Esta representación puede ser asumida tanto por el delegado sindical, elegido por y entre los trabajadores com- 
ponentes de la sección, como por cualquier otro mandatado del sindicato o de la sección, y encuentra sus manifestaciones más evidentes en la defensa preventiva de los trabajadores afiliados ante la propuesta de una sanción — art. 10.3.3 LOLSf - y en la legitimación para negociar convenios de franja en los términos referidos en el art. 87.1 ET.

\section{La representación ejercida por las instancias descentralizadas del sindicato en el ámbito empresarial}

La LOLS garantizó un sistema de representación sindical (Baylos Grau, 2004: 102; Moreno Vida, 2002: 121; García Murcia, 2009: 108) que se sobrepone a los intereses de los afiliados y que, conscientemente, se aparta de las categorías civiles que requieren de mandatos expresos o, a lo sumo, implícitos derivados del acto de adhesión a la asociación correspondiente (Valdés Dal-Ré, 2004: 5). Ahora bien, fue también una opción de política legislativa que se materializó con la aprobación de la Ley Orgánica de Libertad Sindical la que determinó que sólo ciertas secciones sindicales pudiesen asumir funciones con proyección general, o de afectación a la totalidad de la plantilla, siendo la presencia en los órganos unitarios el presupuesto para que la representación exceda el ámbito de los afiliados hasta alcanzar a la totalidad de la plantilla. $\mathrm{O}$, dicho de otro modo, en la medida que las funciones con proyección a la totalidad de la plantilla se reconocen exclusivamente a secciones con presencia probada en la empresa, el legislador exige que estas obtengan el crédito de quienes van a ser los destinatarios últimos de esta actuación representada. Esta afirmación se muestra especialmente gráfica en relación a la aprobación de convenios colectivos estatutarios (Cruz Villalón, 1986: 225; Prados de Reyes, 1991: 188), pues aunque el art. 87.1 ET declara que en los convenios de empresa o ámbito inferior están legitimadas para negociar las «secciones sindicales si las hubiere», también establece que en los convenios que afecten a la totalidad de los trabajadores será necesario que tales representaciones sindicales, en su conjunto, sumen la mayoría de los miembros del comité. Esta representatividad probada también será exigida en los procesos de reorganización productiva (esto es, todas las vicisitudes colectivas disciplinadas en los artículos 40, 41, 47, 51, 82.3 ET) si quien asume la interlocución en nombre e interés de los trabajadores es la representación sindical.

Nadie cuestiona que la representación «institucional» ejercida por las instancias descentralizadas del sindicato se fundamenta en la propia naturaleza del sindicato pues si la finalidad del mismo es, en nuestro ordenamiento jurídico, la persecución de la tutela colectiva de todos los trabajadores (Ojeda Avilés, 1979: 371), con más argumentos, la actuación que puedan desplegar las instancias descentralizadas del sindicato en la empresa podrá ser de afectación a la totalidad de trabajadores presentes en ella sin que lo anterior sea óbice para que 
secciones y delegados también defiendan intereses de carácter particular de sus afiliados lo que, en ocasiones, puede producir tensiones en cuanto a la vocación de tales organizaciones (Ysas Molinero, 2010: 207).

Si la función de los sindicatos no consiste en representar exclusivamente a sus miembros (Puebla Pinilla, 2000: 409), sino que, por su propia configuración constitucional, [SSTC 70/1982, 118/1983, 18/1984, 98/1985 o 187/1987] son representantes institucionales de los trabajadores como categoría, cobra pleno sentido que esta función pueda ser asumida en relación a los trabajadores no afiliados presentes en un ámbito tan reducido como es el empresarial. Cuestión distinta es que la ausencia en el texto constitucional de cualquier referencia al alcance de la representación sindical en la empresa (Valdés Dal-Ré, 2000: XVIII) exija una profunda reflexión sobre los contornos que la sustentan. Parece que la misma se enmarca, en virtud de una interpretación sistemática del art. 28.1 CE y del canon hermenéutico sentado por el art. 10.2 CE, dentro de la vertiente funcional del derecho de libertad sindical que integra el derecho de los sindicatos a ejercer aquellas actividades dirigidas a la defensa y promoción de los intereses que les son propios (Valdés Dal-Ré, 2012: 58) y, lógicamente, todas estas manifestaciones son consideradas, al menos, en su formulación genérica, como parte del contenido esencial del derecho (Elorza Guerrero, 2011: 31 . Desde esta perspectiva, los sindicatos podrán impulsar actuaciones con proyección externa en las que llamen a todos los trabajadores, afiliados o no, que tienen asimismo el derecho a ser protegidos de las posibles represalias derivadas de su participación en las iniciativas convocadas por las organizaciones sindicales, perfilándose una función sindical de expresión de los intereses profesionales que va más allá del concreto círculo de afiliados hasta alcanzar a la totalidad de la plantilla, aun no estando adheridos formalmente al sindicato actuante. En coherencia con este contenido constitucional, las organizaciones sindicales podrán desplegar los medios de acción necesarios para cumplir con las funciones legamente reconocidas entre los que ocupan un lugar destacado la negociación colectiva, el ejercicio del derecho de huelga o el planteamiento de conflictos individuales y colectivos.

Esta representación "legal implícita», en la terminología constitucional (véase la STC 70/1982), obtuvo carta de naturaleza en la ya referida LOLS, y ello a pesar de que su tardía aprobación se debió, según la más cualificada doctrina, "a las dificultadas levantadas por los empresarios a la acción de los sindicatos en los centros de trabajo» (Casas Baamonde, 1990: 604). Tras la promulgación de esta ley se dotó de un marco normativo estable y claramente promocional a las representaciones netamente sindicales a las que la propia Ley atribuye un amplio elenco de funciones y competencias, permitiendo que las mismas puedan asumir la representación de la totalidad de la plantilla. Con esta decisión, la actuación que puedan desplegar las instancias descentralizadas del sindicato en la empresa presenta una doble faz: 
De un lado, la representación de sus afiliados que se justifica por la vinculación voluntaria de estos a la organización sindical (Navarro Nieto, 1993: 24).

De otro, la representación de la totalidad de la plantilla y cuya fuente de legitimación es la LOLS (Casas Baamonde, 1990: 640). Esta representación erga omnes se ha visto claramente reforzada con la modificación operada por el RD Ley 7/2011, de 10 de junio, de medidas urgentes para la reforma de la negociación colectiva (en lo sucesivo RDL 7/2011), pues bien es sabido que la misma estableció una prioridad en la interlocución legal a favor de las representaciones sindicales tanto en relación a la negociación colectiva —art. 87.1 ET—, como para la asunción de la interlocución en todas las vicisitudes de naturaleza colectiva-. Aunque la reforma operada por el RD Ley 7/2011 fue considerada por los sindicatos una verdadera injerencia legal en su capacidad de actuación al no permitir que sea el sindicato quién decida la interlocución sino que normativamente esta competencia se atribuye a la sección sindical (CCOO, 2013: 50), no podemos compartir esta crítica. A nuestro juicio, esta regulación debiera servir como acicate para avanzar en la constitución de instancias descentralizadas del sindicato en todas las empresas pues, conviene no olvidar, que las mismas surgen tras la decisión legítima de un conjunto de trabajadores que, unidos por una común afiliación, deciden impulsar la constitución de una sección sin más requisitos que los preceptuados en los estatutos sindicales. Si las secciones son instancias descentralizadas del sindicato, conformadas por y entre afiliados al mismo en la empresa, a las que la ley les concede una serie de facilidades y garantías para el desarrollo de la acción sindical, esta representación colectiva de intereses de los trabajadores en el ámbito empresarial tiene en las secciones su manifestación más evidente.

\subsection{El elemento constitutivo: la decisión libremente adoptada por trabajadores vinculados por una común afiliación}

La posibilidad de constituir una sección sindical se ha engarzado con el derecho a la actividad que se incluye como contenido esencial del derecho de libertad sindical en su vertiente individual pues su titularidad es reconocida a los trabajadores afiliados y no a los sindicatos, aunque estos podrán promover o alentar su constitución como vía de penetración del sindicato en la empresa. Y, desde esta perspectiva, parece lógico que la LOLS no establezca ninguna limitación a la creación de secciones sindicales pues esta estructura es una manifestación de la libertad de auto-organización del sindicato «que difícilmente podría cercenarse a nivel de legalidad ordinaria ya que seguramente ese cercenamiento no sería conciliable con la libertad sindical que reconoce el art. 28.1 CE, y consiguientemente una legalidad restrictiva no sería respetuosa con el contenido esencial del derecho fundamental" (Cruz Villalón, 1986: 241), siendo también una decisión de los trabajadores que componen la sección la designación de uno 
de ellos como delegado sindical. Cuestión distinta es que sólo gocen de reconocimiento legal aquellos delegados que puedan acreditar el cumplimiento de los criterios contenidos en el art. 10 LOLS.

Ahora bien, el hecho de que la designación del delegado sindical sea una decisión libremente adoptada por quienes constituyen una sección, es una decisión normativa la que reconoce a determinados delegados la condición de representante legal. Este reconocimiento vinculado, como es de sobra conocido, a la acreditación de una presencia probada en la empresa supone atribuir a las secciones sindicales "privilegiadas" y a los delegados por ellas designados una función que excede de la noción de «sindicato-asociación, representante de las voluntades de los afiliados, conforme a las reglas de Derecho Privado, hasta provocar su sustitución por la del sindicato-asociación e institución, representativo (o más) de los trabajadores en cuanto representante de los intereses generales (de los trabajadores en su conjunto)»(Casas Baamonde, 1990).

\subsection{El establecimiento de criterios selectivos para la asunción de esta función. Una decisión legal}

Si las secciones se configuran como divisiones meramente organizativas del sindicato que actúan como instancias descentralizadas del mismo para desarrollar la acción sindical dentro de la empresa (Pérez Anaya, 2011: 88), la representación que asumiesen tendría, en principio, que limitarse a la mejor defensa de los afiliados a la opción sindical correspondiente. Sin embargo, bien es sabido que el art. 8 LOLS reconoce a determinadas secciones la condición de sujeto titular de derechos y competencias con proyección general, es decir, de afectación a la totalidad de la plantilla (Puebla Pinilla, A. 2000: 83), condicionando esta facultad a una determinada implantación en la empresa, medida esta en la presencia en los órganos electivos.

El art. 2.2 LOLS reconoce el derecho a la negociación colectiva a todas las secciones, aunque solo las que pertenezcan a sindicatos más representativos o cuenten con presencia en los comités, es decir, las secciones sindicales con representatividad probada podrán negociar convenios de eficacia general.

Esta exigencia legal trata de garantizar que los representantes sindicales puedan defender en el curso de la negociación el interés de la totalidad de trabajadores y no sólo de los afiliados aunque cabría plantearse qué sentido tiene que las secciones sindicales de los sindicatos más representativos que no cuenten con ningún tipo de implantación en la empresa puedan negociar convenios colectivos de afectación a la totalidad de los trabajadores presentes en esta, es decir, si la sección de un sindicato más representativo que no pueda acreditar presencia en los órganos unitarios debiera tener asegurado, al menos, un puesto en la comisión negociadora, interpretación que es la que parece colegirse del art. 8.2 b) LOLS (Agut García, 2004: 45). 
Respecto a la designación de un delegado sindical, la opción legal por un sistema basado en la designación por y entre los trabajadores afiliados en detrimento de la elección directa del sindicato (Cruz Villalón, J. 1986: 246), alternativa posible conforme a lo dispuesto en el art. 3.a) CC núm. 135 de la OIT de 23 de junio de 1971, relativo a la protección y facilidades que deben otorgarse a los representantes de los trabajadores en la empresa (Ratificado por Instrumento de 8 de noviembre de 1972, BOE 4.7.1974) y en el que, como es sabido, se admite que los representantes sindicales sean «nombrados o elegidos por los sindicatos o afiliados a ellos», supone dotar de un amplio margen de autonomía a las secciones que valorarán por criterios de oportunidad la decisión de designar a alguno de sus integrantes como tal. Cuestión distinta es que los efectos jurídicos que lleva aparejado tal condición, es decir, la designación de un delegado sindical "cualificado" en los términos contenidos en el art. 10 LOLS, someta a esta decisión a la observancia de los siguientes requisitos:

En primer lugar, es obvio que el delegado sindical ha de ser trabajador de la unidad en la que se haya constituido la sección sin que quepa conformar «el cuerpo electoral con afiliados ajenos, en el plano laboral y funcional, a la empresa o centro de trabajo» (Álvarez de la Rosa, 1991: 106).

En segundo lugar, porque siendo cierto que su efectiva designación se caracteriza por una mayor laxitud que la relativa al proceso electoral estatutario, esta mayor flexibilidad no puede alterar la fórmula de elección, esto es, que la facultad del nombramiento y, en su caso, destitución la ostenten los trabajadores de la sección y no el sindicato. Y, en este sentido, alguna doctrina de suplicación —véase la doctrina sentada en la STSJ Madrid 10.4.1992 (R.o 4919/1992) y en la STSJ Galicia 16.12.1992 (R.o 4450/1992) — ha señalado que aunque «el sistema español de acción sindical en la empresa exige que el representante del sindicato sea un trabajador de la misma sin que lo anterior requiera una mecánica de elección democrática que tenga que efectuarse formalmente (a diferencia del proceso externo y formal establecido para la elección de la representación unitaria) lo que concuerda con la naturaleza de asunto interno del sindicato que tiene la designación del delegado sindical, que deberá resolverse según sus estatutos y que no permite control distinto al que el sindicato y los trabajadores afiliados ejerzan».

Y, en tercer lugar, en lo que hace a la superación de una determinado volumen de empleo, bien es sabido que la STC 173/1992 confirmó la constitucionalidad de la regulación legal al recordar que esta figura ha de ser calificada como contenido adicional de un derecho fundamental y, por tanto, siendo cierto que, desde la perspectiva del art. 28.1 CE, no sería constitucionalmente admisible una norma que, atribuyendo algunos medios de acción a ciertos sindicatos, privara a otros de ellos siempre que los mismos fueran inexcusablemente necesarios para que la organización sindical pudiera realizar las funciones consideradas como contenido esencial del derecho, pero comoquiera que la designación de es- 
tos delegados se enmarca dentro del contenido adicional, su interpretación «no tiene que ser siempre la más favorable», concluyendo entonces que la exigencia legal contenida en el art. 10.1 LOLS en lo que hace al número de trabajadores es plenamente respetuosa con la naturaleza atribuida a este representante legal. Pacífica esta cuestión, la litigiosidad se ha centrado en torno a dos aspectos:

En primer lugar, la ausencia en la LOLS de criterio alguno para proceder al cómputo de trabajadores, de modo que se entendía que en él habría de incluirse a la totalidad de los trabajadores. Esta interpretación planteaba el problema de determinar si esta cifra debía tomarse de forma puramente estática, atendiendo al momento preciso en que se constituyese la sección o si, por el contrario, debía atenderse a un criterio más flexible que tuviese en cuenta la variabilidad del número de trabajadores contratados a lo largo del año. Tuvo que ser la STS 26.4.2010 (R.o 1777/2009) la que sostuviese la necesidad de aplicar analógicamente el criterio contenido en el art. $72 \mathrm{ET}$, de modo que se incorporarán al cómputo los fijos discontinuos y los temporales, cuyo contrato tenga duración superior al año, y de forma proporcional al número de días trabajados de aquéllos, cuyo contrato tenga una duración inferior, entendiendo que debe contarse a un trabajador más por cada doscientos días de trabajo o fracción. Con esta decisión, se evita además que tanto sindicatos como empresas puedan usar criterios espurios para la designación de estos delegados (momentos de mayor actividad que no reflejen fidedignamente la plantilla real). La presencia en los órganos unitarios se configura entonces como el presupuesto necesario para proceder a la designación toda vez que el art. 10.2 LOLS utiliza los resultados del proceso electoral para establecer, con carácter de mínimo, el número de delegados sindicales si bien el propio legislador establece una cautela en este sentido ya que todas las secciones que no hayan obtenido el $10 \%$ de los votos estarán representadas por un único delegado sindical, obviamente uno por cada sindicato que haya concurrido a las elecciones al comité de empresa y no haya alcanzado dicho porcentaje. Conviene recordar que el art. 71.2 b) ET establece que para entrar en el reparto de puestos en el seno del comité se exige el 5\% de los votos en cada colegio electoral, habiéndose planteado si los sindicatos que hubieran superado este porcentaje, aun cuando no hubieran conseguido finalmente ningún miembro en el mismo, podían contar con un delegado sindical con las garantías previstas en la LOLS. La STS 23.5.1990 (RJ 1990/4991) zanjó esta cuestión señalando que la exigencia contenida en el art. 10.2 LOLS, tanto desde una interpretación literal como de acuerdo con el espíritu y finalidad de la norma, no es la de que cualquier grupo de afiliados a un sindicato pueda elegir delegados que alcancen los derechos, privilegios y garantías que el art. 10.3 LOLS reconoce solo a los que han justificado su implantación en la empresa, es decir, a las secciones que no hayan obtenido el 10\% de los votos pero que sí que tengan presencia en el comité.

El coste que genera esta figura al empresario justifica que la facultad de designar delegados sindicales se reserve exclusivamente a los sindicatos implanta- 
dos en la empresa sin que sea suficiente, a diferencia de lo que ocurre con los derechos reconocidos en el art. 8.2 LOLS, la condición de sindicato más representativo, (Luján Alcaraz, 2003: 165; Prados de Reyes, 1991: 188; Sáez Lara, 2005: 115; Sáez Lara, 1992: 175).

Sentado lo anterior, la principal deficiencia que, a nuestro juicio, tiene la regulación legal es la utilización de una dimensión de plantilla tan elevada como la exigida en el art. 10.1 LOLS hasta el punto de que proponemos su minoración mediante una reforma a tal efecto. Las profundas transformaciones en las estructuras productivas han tenido como consecuencia directa una reducción en las plantillas lo que, sin ningún género de dudas, supone una serie limitación al desarrollo de la acción sindical en este ámbito, parcialmente solventado porque la misma se está instrumentalizando mediante la sindicalización de la representación unitaria. De no prosperar la reforma normativa en el sentido propuesto, no queda sino acudir a la negociación colectiva (Rodríguez Sañudo, $2007,152)$ para que rebaje los requisitos legales, siendo relativamente frecuentemente que los convenios colectivos minoren el número de trabajadores exigidos para proceder a la designación del delegado sindical o, en su caso, que incrementen el número de delegados objeto de designación, contemplando cláusulas de mejora a este respecto que normalmente se vinculan al cumplimiento de otros requisitos, a saber: una determinada presencia en los órganos de base electiva, la condición de sindicato más representativo o, a nuestro juicio, el criterio más respetuoso, la acreditación de una cierta implantación en la concreta empresa, medida ésta en la audiencia electoral obtenida o en el número de afiliados. Enjuiciando la legalidad de estos criterios, véanse las SSTS 14.6.2004 (R.o 124/2004), 15.7.2005 (R.o 187/2003), 16.1.2006 (R.o 213/2006), 5.3.2007 (R.o 187/2004), 14.3.2007 (R.o 4477/2005) o la STS 24.10.2017 (R. ${ }^{\circ}$ 100/2016) y así, «si el convenio permite nombrar un delegado, asimilable al delegado LOLS, si la empresa tiene más de 150 trabajadores y siempre que la sección acredite esta representatividad, podrá nombrarse uno por cada sección que cumpla estos requisitos). Sobre el tratamiento convencional, es obligada la consulta de (Luján Alcaraz, 2003: notas 175 a 181; Rodríguez Sañudo, 2007: 152) Véanse también CC Iberia LAE (BOE 7.9.2018) o en el ámbito sectorial el CC Empresas Organizadoras de Juegos de Bingo (BOE 19.6.2015) que contempla, a este respecto, que «los sindicatos podrán constituir Secciones Sindicales, conforme a lo dispuesto en la Ley Orgánica de Libertad Sindical. En las empresas con más de veinte trabajadores que cuenten con un 50\% de afiliados, la sección representará los intereses sindicales de sus afiliados ante la dirección de la empresa contando con un Delegado/a Sindical, que gozará de los derechos y garantías fijados para los Delegados/as de Personal y miembros de los Comités de empresa, salvo en lo que se refiere a reservas de horas».

La negociación colectiva deberá, en todo caso, respetar los principios que se prescriben en la propia Ley, a saber: 
a) La utilización de la dimensión de la plantilla para determinar el número de delegados.

b) Que todas las secciones sindicales que hayan alcanzado el 10\% de los votos en la elección al comité de empresa tengan el mismo número de delegados sindicales siempre que en su constitución se haya utilizado la misma unidad de referencia.

Si los criterios convencionales no impiden la acción de los sindicatos que cuenten con presencia o implantación en la empresa, no habrá obstáculo en admitirlos como ajustados a Derecho y respetuosos con el contenido adicional del derecho y sólo, a falta de acuerdos específicos, habrá que observar las reglas previstas en el precepto legal. Respecto a la naturaleza de este delegado sindical, este sujeto tiene legamente atribuida la representación de la sección sindical, pudiendo asumir sin necesidad de apoderamiento expreso las competencias reconocidas en el art. 10.3 LOLS, sin perjuicio de que los Estatutos Sindicales o los reglamentos de la sección en cuestión puedan determinar límites a su actuación (Puebla Pinilla, 2000: 83). Como refirió la STC 292/1993, los delegados sindicales «son representantes o mandatarios de las secciones», de modo que «no precisan apoderamiento notarial para representar a la sección, puesto que ya tiene atribuida legalmente esta representación» (STS 10.10.2005 (R.* 28/2004).

Desde esta perspectiva, la representación asumida por el delegado sindical presenta, al igual que la asumida por las secciones sindicales, una doble faz, habida cuenta que este delegado es, por decisión expresa de la LOLS, el representante de la sección y lo es en sus términos más estrictos, es decir, está obligado a actuar de acuerdo a lo mandatado por la sección que lo designó, quedando vinculado con esta a través de un mandato privado. O, dicho de otro modo, el delegado sindical no tiene razón de ser si se le desconecta de la sección a la que representa, debiendo respetar lo mandatado por esta y, en su caso, por lo preceptuado por el sindicato de pertenencia pero, de otro lado, tiene legalmente atribuida una representación con alcance general, siendo el apartado tercero del art. 10.3 LOLS el que reconoce a este sujeto, siempre que no forme parte del comité de empresa, el derecho a ser oído por la empresa previamente a la adopción de medidas de carácter colectivo, alcanzando con esta actuación a una "colectividad indeterminada de trabajadores» (Álvarez de la Rosa, M. 1991: 163), estén afiliados o no.

Esta consulta debiera permitir que el empresario conozca la postura del delegado (y de la sección a la que él representa) y supone una evidente manifestación de una representación de alcance general asumida por este sujeto pues de la dicción legal es obvio que la referida consulta deberá efectuarse tanto si las medidas propuestas por la empresa tienen una proyección general como si se circunscriben a un concreto segmento de trabajadores, afiliados o no (Rodríguez-Piñero y Cruz Villalón, 1987: 96). Estamos, por tanto, ante un derecho autónomo que podrá ser 
ejercido en tanto que el ordenamiento prevea la intervención de la representación unitaria en decisiones con una proyección colectiva. En relación a su ejercicio, habrá de garantizarse un tiempo suficiente para que el delegado sindical pueda expresar de manera motivada su parecer, y en lo que hace a su alcance objetivo, la amplitud de la previsión legal se extiende a una multiplicidad de vicisitudes.

El derecho de audiencia podrá ser ejercido tanto si se trata de medidas en las que está prevista la intervención consultiva de la representación unitaria (art. 64.1.5 ET) como en los supuestos en los que se prevé la posibilidad de alcanzar un acuerdo con la representación legal de base estatutaria (entre otras, recibo de salarios —art. 29.4 ET—, distribución irregular de la jornada —art. 34 ET—), aunque las de mayor relevancia serán las vinculadas a modificaciones de carácter colectivo que prevean procesos cualificados de consultas, a saber: traslados, modificaciones sustanciales, reducciones, suspensiones de jornada, transmisiones de empresa, despidos colectivos e inaplicaciones convencionales pero también y de manera convergente a las competencias reconocidas a las representaciones unitarias en los artículos 64.5 y 6 ET, debiendo ser oídos ante aquellas decisiones que pudieran provocar cambios relevantes en cuanto a la organización del trabajo y a los contratos de trabajo en la empresa o sobre la adopción de eventuales medidas preventivas. Una interpretación sistemática del derecho que asiste a los delegados sindicales que no formen parte del comité de empresa fuerza a sostener que dichos representantes tienen también derecho de audiencia previa, (Sala Franco, T. 2010, 583). La empresa no está obligada a dar audiencia al delegado sindical de una sección sindical no ajustada a la LOLS, porque no concurren los requisitos del art. 10.3 LOLS (STS 9.5.2018, R. ${ }^{\circ}$ 3051/2016). Ahora bien, si la interlocución en el período de consultas se asume por las secciones sindicales — sujeto preferente tras la promulgación del $\mathrm{RD}$ Ley 7/2011—, habría de entenderse amortizado el derecho que asiste al delegado sindical en la medida en que ya habrá tenido conocimiento de la decisión empresarial. Cuestión distinta es que algún delegado sindical no haya participado en este proceso, en cuyo caso, mantiene incólume su derecho a ser oído con anterioridad a la adopción de la medida.

Finalmente cabe referir que es relativamente frecuente que la negociación colectiva incorpore cláusulas que amplían o mejoran los derechos sindicales de afiliados en la empresa, secciones sindicales y delegados sindicales o, en su caso, que se pacte una financiación específica para la actuación de las representaciones presentes en su ámbito.

Pues bien, para admitir la legalidad de este cláusulas, una pacífica doctrina del TS —véanse, entre otras, las STS 23.4.2013 (R.o 206/2011), 10.6.2003 (R. ${ }^{\circ}$ 67/2002) - entiende que su inclusión ha de hacerse de manera que se respete el derecho de libertad sindical de todos y cada uno de los sindicatos presentes en la empresa, es decir, «la distribución de ayudas a la actividad sindical concretada exclusivamente en los sindicatos firmantes del convenio, con exclusión 
de otras fuerzas sindicales que ostentaban representatividad suficiente para haber intervenido en la propia negociación del mismo, exige de una justificación objetiva y razonable que elimine cualquier atisbo de ataque a la libertad sindical».

Desde esta perspectiva, la mera circunstancia de la firma del convenio no podría servir de razón para excluir a un sindicato que, a priori, ostenta implantación y representatividad, máxime si la exclusión lo es a una ventaja o beneficio que no encuentra razonable conexión con otra circunstancia distinta de la de su postura en la negociación. Esta actuación podría, incluso, constituir una injerencia prohibida, tal y como se define en el párrafo segundo del art. 13 LOLS, en tanto pudiera cercenar la acción sindical del sindicato por el mero hecho de no haber firmado el convenio $y$, de este modo, estar interfiriendo en la propia postura sindical.

A este respecto, es reiterada la jurisprudencia —entre otras muchas, SSTS 15.7.2013 (R.o 178/2003), 15.11.2004 (R.o 90/2004), 9.12.2005 (R.o 183/2003), 18.9.2007 (R. $\left.{ }^{\circ} 82 / 2005\right)$ - que considera que es «apreciable una injerencia en el sentido contemplado por el art. 13.2 LOLS, en relación con el art. 2 del Convenio 98 de la OIT "porque, aunque no exista de forma explícita una finalidad de control directo, sí que concurren dos elementos de riesgo importantes que no son ajenos a la finalidad de interdicción de los actos de injerencia. Estos riesgos son, por una parte, la creación de incentivos económicos o de otra índole para la aceptación del convenio que operan sobre el interés particular de la organización sindical y al margen del interés general de los trabajadores representados por ésta, que en el convenio estatutario no son únicamente sus afiliados, y, por otra, la imposición de una desventaja para otros sindicatos que no suscriben el convenio".

Sentado lo anterior, el tratamiento jurisprudencial es tan severo que parece que «en algunos momentos prevalece la defensa de la libertad sindical negativa frente a la positiva, lo que repercute en la poca difusión de este tipo de cláusulas convencionales en el modelo español de relaciones laborales. Falta seguridad jurídica en el reconocimiento, a través de cláusulas convencionales, de derechos colectivos incrementados a determinados sindicatos y a sus afiliados, normalmente los más representativos o implantados en la empresa, pues el mismo es aceptado en escasas ocasiones por la jurisprudencia, exigiéndose que, en su caso, las diferenciaciones sean razonables, proporcionadas, sean pactadas y respondan a criterios de diferenciación objetivos» (Ferradans Caramés, 2015: 155).

\section{La prioridad de la interlocución sindical: una opción de política legislativa}

En una opción de política del Derecho en favor del sindicato, coherente con nuestro modelo constitucional, el RD Ley 7/2011 estableció una preferencia sindical que se refleja normativamente en los distintos supuestos de periodos 
de consulta y negociación previstos en el texto estatutario, a saber: artículos 40, $41,47,51,82.3$ y 87.1 del ET aunque esta preferencia se condiciona a la concurrencia de determinada implantación en este ámbito, habida cuenta que solo podrán asumir esta negociación las secciones sindicales representativas, es decir, aquellas que sumen la mayoría de los miembros del comité de empresa o entre los delegados de personal.

La reforma efectuada en el ańo 2011 zanja, al tiempo, el debate de si el sindicato como órgano externo a la empresa podía recabar para sí la condición de parte de un convenio colectivo de ámbito de empresa o inferior al atribuir la legitimación a las secciones. Este reconocimiento es plenamente respetuoso con el propósito legislativo de profundización de la democracia sindical (STC 208/1993), y había sido ya sostenido tras la aprobación de la LOLS por parte de la doctrina (Escudero Rodríguez, R. 1985: 196). Defendiendo la tesis contraria, es decir, que la negociación directa por el sindicato o indirecta a través de sus órganos es un problema de régimen interno o de oportunidad, (Álvarez de la Rosa, 1991: 140). La decisión adoptada por el RD Ley 7/2011 se aparta de la tesis defendida por el TS en el sentido de considerar una cuestión interna del sindicato el órgano legitimado para negociar - vid, entre otras, las SSTS 28.2.2000 (R.o 2040/1999) y 16.9.2004 (R.o 129/2003)—.

El hecho de que sean las secciones las legitimadas para negociar en este ámbito supone dotar a estas instancias de una cierta autonomía en su actuación, pues es evidente que las mismas podrán escuchar al sindicato de pertenencia, pero la obtención de la mayoría estatutaria será requisito suficiente para dotar de eficacia personal general al acuerdo adoptado, incluso aunque el sindicato se muestre contrario a esta decisión.

Ahora bien, tanto las secciones sindicales que son, en puridad, instancias descentralizadas del sindicato como los delegados sindicales están sujetos a las instrucciones y dictados establecidos en los Estatutos Sindicales y en las actuaciones aprobadas en los Congresos (especialmente en los criterios de negociación), de forma que la separación de las instrucciones será un problema de legalidad sindical, no siendo infrecuente que existan tensiones, máxime cuando el sindicato local o la confederación impone una estrategia que las secciones sindicales de las concretas empresas rechazan en todo o en parte, (Ojeda Avilés, 2000). Por ejemplo, en la SAN 22.9.2014 (Proc. 76/2014) se dirime la adecuación legal de la destitución de un delegado sindical «en el contexto de la firma por los representantes de USO en la empresa, en contra de la política de su sindicato, de un convenio de empresa que ha de primar sobre el sectorial».

Sentado lo anterior, la preferencia legal no opera «por decisión de una o varias secciones sindicales» (CCOO. 2011: 57) sino que el ET exige un acuerdo previo de las representaciones sindicales, tendente a intervenir en la negociación en representación de la totalidad de trabajadores, sin que necesariamente «se- 
mejante decisión se suscriba por unanimidad o por la mayoría de ellas. O, dicho de otro modo, lo requerido es que las secciones sindicales que la respalden cuenten con la mayoría de los representantes unitarios existentes en la unidad de negociación, sin que tales secciones sindicales puedan excluir a aquellas otras que, contando con representación en los órganos unitarios, manifiesten su voluntad de participar en el acuerdo de iniciar la negociación» (García Quiñones, 2013: 42).

El derecho a la negociación colectiva forma parte, de acuerdo con una pacífica jurisprudencia del TC, del contenido esencial de la libertad sindical. Ya la STC 73/1984 señalaba que «la asignación de un menor número de representantes en la comisión negociadora y la reducción consiguiente de su capacidad de acción dentro de la misma, como resultado de una minoración injustificada del índice de representatividad atribuido a un sindicato, podría calificarse también como lesión del derecho reconocido en el art. 28.1 de la Constitución». Sentadas estas premisas, no toda decisión acerca del índice de representatividad de un sindicato afecta a su derecho fundamental de la libertad sindical ni siquiera cuando, como resultado de la misma, se reduzca la participación de dicho sindicato en la comisión negociadora de un convenio colectivo o se recorten sus posibilidades de actuación dentro del sector correspondiente. En muchos casos, «la minoración de la representatividad y de la capacidad de obrar de un sindicato, al igual que su exclusión de la mesa de negociaciones, puede estar justificada, y que, si efectivamente se funda en un motivo jurídicamente aceptable, una actuación de ese tipo no supone lesión alguna de la libertad sindical». Ello pone de manifiesto que la disminución del número de representantes de un sindicato en la comisión negociadora de un convenio colectivo, derivada de un reajuste de la cuota representativa asignada a cada uno de los participantes, sólo podrá calificarse como lesiva de la libertad sindical si tiene su origen en una decisión contraria a la ley o es claramente arbitraria», (Palomeque López, 2009, 29).

La existencia de un número máximo de miembros en la mesa negociadora (trece, conforme a lo dispuesto en el art. 88.4 ET e idéntico número es referido también en el art. 41.4 ET) puede suponer que todas las secciones con legitimación inicial tengan «derecho, cuando menos a participar en la designación de los componentes de dicho banco social, aun cuando pueda ser impracticable por todas las limitaciones numéricas que todas hayan de contar con algún miembro» (STC 137/1991). O, dicho de otro modo, comoquiera que el sistema de reparto de puestos en la mesa negociadora se determina en función de la representatividad, la exclusión de alguna de las legitimadas en la composición final de la comisión no necesariamente ha de ser considerada como una conducta vulneradora de la libertad sindical (Álvarez Cuesta, 2006, 169) sino que esta lesión sólo se producirá cuando la misma tenga lugar de modo arbitrario, antijurídico y carente de justificación como sucede en el supuesto de las minoraciones de presencia sindical en las comisiones creadas con facultades negociadoras. 
La STS 18.1.1993 (R.o 1682/1991) recuerda, a este respecto, que «en supuestos en los que las representaciones sindicales que negocian suman el porcentaje representativo que expresa (el necesario para la adopción de acuerdos -el $60 \%$ en aquel momento), pueden excluir de la negociación a otras representaciones sindicales, que, como las recurridas, tiene aptitud para intervenir en dicha negociación o legitimación «inicial», en tanto que cumplen las condiciones que dispone el art. 8.2 de la Ley Orgánica de Libertad Sindical» pues dicha exclusión podría suponer un atentado a la libertad sindical de estas otras representaciones sindicales.

Que la legitimación sea legalmente atribuida a las secciones implica plantearnos si la modificación estatutaria impide, de facto, la negociación de otros órganos o estructuras pertenecientes al sindicato. Hasta la reforma operada por el RD Ley 7/2011, la expresa referencia a las «representaciones sindicales», no a las «secciones», era el argumento que permitió sostener que era una opción del sindicato la concreta determinación del sujeto negociador (Baylos Grau, A. 2010: 35) pues «si las secciones sindicales son meros órganos del sindicato (...), en principio, la negociación directa por el sindicato o indirecta a través de sus secciones es un problema de régimen interno». Sin embargo, la mención expresa a las secciones sindicales en el texto estatutario nos insta a defender que existe en el RD Ley 7/2011 una clara orientación hacia la empresa lo que hace "cambiar de plano el poder de negociación sindical, de la federación de rama a la sección sindical» (Baylos Grau, A. 2011: 10), siendo uno de los efectos previsibles de este cambio normativo la revalorización de estas instancias descentralizadas del sindicato en las empresas.

Desde círculos sindicales, aun valorando positivamente esta reforma en tanto que la «referencia a las secciones sindicales es un avance respecto a la sindicalización en las empresas» (CCOO, 2013: 43), consideran que la preferencia debería haberse efectuando reconociendo al sindicato y no a las secciones la legitimación. Pero comoquiera que no ha sido así, ante un conflicto entre el sindicato y la sección, habrá que estar a la legislación vigente, esto es, priorizando a la sección o secciones legitimadas. La legitimación plena exigirá obviamente acreditar la presencia mayoritaria de la sección o secciones en los órganos unitarios, conforme a lo dispuesto en el art. $88 \mathrm{ET}$, es decir, «la mayoría exigida se determina sobre el conjunto de los miembros de comités de empresa y delegados de personal que existan en la unidad de negociación, por lo que no es incompatible con el cumplimiento del requisito el hecho de que las secciones no cuenten con la mayoría de representantes unitarios elegidos en algún centro o que en él no haya representación unitaria» (Garate Castro, 2012: 133). Este cálculo habrá de efectuarse tomando el resultado que en las elecciones a miembros de comités de empresa y delegados de personal haya sido atribuido al sindicato al que pertenezca cada sección, no el número de representantes unitarios con los que el sindicato cuente en el momento de la adopción del acuerdo. 
Ahora bien, lo que la Ley no aclara si esta reivindicación puede formularse en cualquier momento o si, por el contrario, la sección o secciones dominantes han de decidir tomar el control desde el principio (Gómez Abelleira, 2011: 135). Parece más compatible con el deber de negociar de buena fe que la decisión se tome al principio del proceso negociador, no durante el desarrollo $y$, sólo ante la ruptura del proceso negociador en curso, con agotamiento del deber de negociar de buena fe, cabrá la reapertura del proceso con diferentes sujetos intervinientes. Con anterioridad a la reforma, la selección de un interlocutor —unitario o sindical — vinculaba definitivamente al empresario a las reglas de legitimación derivadas de dicha decisión, STS 8.10.2009 (R.o 161/2007). Es más, alguna doctrina judicial —en relación al CC de la empresa Leroy Merlin, véase SAN 25.7.2007 (Proc. 50/2007), sentencia que fue posteriormente confirmada por la STS 4.3.2010 (R. $\left.{ }^{\circ} 134 / 2007\right)$ - ya ha calificado como una conducta contraria a la libertad sindical la irrupción irregular de un órgano unitario «en una negociación propuesta por la empresa a nivel sindical», máxime cuando queda acreditado que dicha decisión no tiene otra finalidad que, bajo la apariencia de un cambio negocial, la de excluir a las secciones legitimadas del proceso.

Ahora bien, no toda negociación con las representaciones de base electiva puede ser considerada una conducta contraria al derecho a la libertad sindical y, en este sentido, la STC 119/2014 ya tuvo que abordar si la preferencia del convenio de empresa en los términos contenidos en el art. 84.2 ET podría ser una conducta contraria al derecho de libertad sindical en relación al derecho que asiste a los sindicatos a ordenar la estructura de negociación colectiva de la forma que estimen más conveniente. La regulación estatutaria no merece, a juicio del máximo intérprete constitucional, reproche alguno "pues resulta obligado recordar que el art. 37.1 CE ordena garantizar el derecho a la negociación colectiva de "los representantes de los trabajadores», sin exigir que esta representación sea necesariamente de naturaleza sindical. No en vano el legislador, en el legítimo ejercicio de su libertad de configuración del derecho, ha optado desde antiguo por otorgar legitimación en los convenios de empresa tanto a la representación sindical como a la unitaria. A mayor abundamiento, «desde la perspectiva constitucional tampoco es reprochable que un convenio de empresa negociado por la representación unitaria en virtud del art. 37.1 CE entre en concurrencia y goce de preferencia aplicativa sobre un convenio sectorial negociado por los sindicatos, pues del texto constitucional no se deduce que la negociación colectiva sindical haya de tener prioridad absoluta sobre la negociación colectiva realizada por otros representantes de los trabajadores».

Otra cuestión de enorme complejidad jurídica (y notable relevancia práctica) que la legislación no ha resuelto es la de determinar si las secciones sindicales podrán asumir la representación de la totalidad de la plantilla en empresas con una pluralidad de centros en los que algunos cuenten con representantes unitarios y otros que carezcan de ellos, existiendo dos interpretaciones al respecto. 
La primera de ellas sostiene que, si las secciones sindicales de empresa ostentan la mayoría conforme a la exigencia estatutaria, las mismas estarán legitimadas para negociar por todos los trabajadores de la empresa. Esta tesis, ha sido mantenida por la Audiencia Nacional en las sentencias de 18.6.2012 (Proc. 80/2012), 26.4.2013 (Proc. 76/2013), 11.11.2013 (Proc. 198/2013), 17.6.2014 (Proc, 125/2014) o SAN 17.3.2018 (Proc. 50/2018), entendiendo, a este respecto, que las secciones sindicales mayoritarias «representan a la totalidad de los trabajadores de la empresa, fuere cual fuere su implantación en cada uno de los centros de esta, lo cual impide, necesariamente, que compartan esa representación general con representatividades particulares de cada centro de trabajo».

Sin embargo, es dable una segunda interpretación, cual es que la legitimación de las secciones se extenderá a la totalidad de la plantilla, siempre y cuando a ello no se opongan los trabajadores que presten servicios en centros que no cuenten con representantes legales de base estatutaria puesto que si estos, legítimamente, deciden designar una comisión ad hoc, conforme a las reglas previstas en el art. 41.4 ET, las secciones sindicales no podrán asumir esta representación de carácter global sino sólo la de los centros que no hubiesen designados a los mandatados ad hoc, debiendo, en tales casos, conformarse una comisión híbrida compuesta por representantes sindicales y, en su caso, por los trabajadores mandatados por los centros sin representación. Esta solución, aunque pudiera colegirse de la previsión contenida en el art. 41.4 ET, no tiene sentido, máxime si pensamos que la acreditación de la mayoría de los representantes unitarios es título bastante para que las secciones sindicales cuenten con legitimación plena, conforme a lo dispuesto en el art. 88 ET. Es más, si se asumiese esta interpretación, la misma implicaría que las secciones sindicales que cumpliesen el requisito de mayor representatividad a nivel de empresa se verían sustituidas por una representación ad hoc; efecto este que podría ser calificado como contrario a nuestro modelo constitucional y los tratados internacionales que reconocen el derecho a la negociación colectiva y a la libertad sindical.

A nuestro juicio, obtenida la mayoría exigida en el art. 41.4 ET, la legitimación de las secciones alcanza a la totalidad de los trabajadores de la empresa sin necesidad alguna de «aditamento democrático por parte de los trabajadores a través de la designación de las comisiones ad hoc», compartiendo que "la designación en tales casos de comisiones ad hoc por parte de los centros carentes de representación unitaria con pretensión de constitución de una comisión negociadora hibrida constituiría en puridad un atentado contra la libertad sindical (arts. 28.1 y 37.1 CE) a salvo, claro está, de su libre aceptación por todos y cada uno de los sindicatos legitimados, y con posibilidad, en todo caso y en cualquier momento, de prescindir del consenso de aquellos» (Benavente Torres, 2014: 131). Lo antedicho permite concluir que las secciones que acrediten representación en los centros afectados por las medidas de flexibilidad, interna o externa, tienen derecho a ser convocados a los periodos de consultas, así como a 
participar en su negociación en la proporción correspondiente, de modo que la exclusión injustificada de la sección comporta una vulneración de la libertad sindical (STS 6.6.2018, R.o 149/2017).

Este favor por las secciones sindicales no se extiende a las reglas que disciplinan la legitimación para asumir la negociación colectiva estatutaria en los nuevos ámbitos de negociación incorporados por el RD Ley 7/2011, a saber: grupos de empresas o redes empresariales, sino que las reglas de legitimación en estas unidades se remiten a lo dispuesto en el art. 87.2 ET. Será, por tanto, una decisión interna del sindicato la determinación de quienes conformarán el banco social sin que necesariamente tengan que estar presentes las secciones sindicales de las empresas afectadas por la negociación. A nuestro juicio (Nieto Rojas, P. 2011), esta solución legal no sólo supone una limitación competencial directa a las representaciones unitarias de cada una de las empresas pues, como es obvio, no podrán formar parte del banco social sino también para los sindicatos con implantación en la medida que la aplicación de las reglas de legitimación propias de los convenios sectoriales impide, de facto, su participación si no acreditan un mínimo del 10 por ciento en el ámbito geográfico y funcional del convenio.

Que la legitimación se haya establecido a través de una regla sindical de aplicación exclusiva y excluyente supone un reforzamiento del papel que han asumido las Federaciones Sindicales en este proceso pero, al tiempo, implica un alejamiento consciente de la doctrina anterior —véase la STS 6.5.2004 (R.o 25/2003) — que, al menos, en el supuesto de "grupos de empresas con estructura organizativa relativamente simple» había admitido la legitimación según las reglas propias de los convenios empresariales; solución, a nuestro juicio, mucho más respetuosa con el modelo legal.

\section{La libertad de auto-organización como fundamento de la elección del ámbito de los órganos representativos de base sindical}

La decisión del ámbito de configuración de las instancias sindicales es un derecho de los sindicatos, habida cuenta que su constitución no genera deberes prestacionales automáticos al empresario sino simplemente un deber de tolerar o de no interferir en su creación (Cabeza Pereiro, 2004, 530). La aseveración anterior explica una cierta flexibilidad estructural en el modelo organizativo, claramente reforzada con la STS 18.7.2014 (R.o 91/2013) en relación al ámbito en el que cabe la designación de delegados sindicales, frente a la rigidez que define a la representación de base estatutaria, centrada en la noción de centro de trabajo.

Parece lógico que la LOLS no establezca ninguna limitación a la fijación del ámbito de actuación de las secciones pues como ya advirtió la STS 1.6.1992 
(R. ${ }^{\circ}$ 2094/1991 y que ha sido recientemente refrendada en la STS 8.2.2018 (R. $\left.{ }^{\circ} 119 / 2018\right)$, su constitución es una manifestación de la libertad del sindicato "que difícilmente podría cercenarse a nivel de legalidad ordinaria ya que seguramente ese cercenamiento no sería conciliable con la libertad sindical que reconoce el art. 28.1 CE, y consiguientemente una legalidad restrictiva no sería respetuosa con el contenido esencial del derecho fundamental». De ahí que se haya admitido que la sección sindical pueda constituirse agrupando centros de trabajo si esta decisión se cohonesta con la propia organización de la empresa (véanse las SSTS 21.6.2016 (R. ${ }^{\circ}$ 182/2015) y 7.3.2017 (R.o 101/2016), admitiendo este ámbito superior al centro e inferior a la empresa).

Ahora bien, cabría plantearse cuál es el margen real de autonomía de los afiliados de la sección para determinar su ámbito de actuación, es decir, si el tenor literal del art. 8.1a) LOLS fuerza a una previsión expresa de los estatutos sindicales para que puedan constituir la sección en el ámbito que estimen conveniente o habrán de atender a las instrucciones sindicales, (Agut García, 1997: 197).

Parece que, ante un conflicto de voluntades acerca de la oportunidad de constituir las referidas secciones en la empresa o en el centro, no prevalecerá ninguna de las dos puesto que ninguna es suficiente para proceder a la constitución de la sección mientras que si no hubiese un pronunciamiento en los estatutos del sindicato en cuestión, una interpretación finalista de la norma fuerza a admitir la posibilidad de constitución en el ámbito que los afiliados dispongan, a diferencia de si el sindicato se muestra manifiestamente contrario a su creación, en cuyo caso, se vedaría tal posibilidad (Agut García, 1997, 300) mientras que otros autores admiten su creación ante el silencio estatutario, (Albiol Montesinos, 1990, 171).

En todo caso, este es un problema que se diluye en la práctica, dada la estructura confederal de los sindicatos con mayor implantación pues en todas las regulaciones estatutarias analizadas se contempla el centro de trabajo como ámbito preferente para la constitución de las referidas secciones. - puede consultarse la configuración normativa de las secciones sindicales en diversos estatutos de Confederaciones y Federaciones en (Pérez Anaya, 2011: 93)—, siendo la única limitación en este sentido la dirigida a que no se puede rebasar el ámbito que fija el sindicato en sus estatutos fundacionales. Ahora bien, las secciones sindicales tienden, en la práctica, a conformarse a imagen y semejanza de los órganos unitarios, debiendo justificar el mimetismo, aparte de las habituales inercias y cautelas, en condicionantes legales que, de forma indirecta, influyen en la libertad de elección del ámbito de las instancias sindicales.

En primer lugar, porque siendo cierto que los sindicatos son relativamente libres para decidir el ámbito de las referidas secciones, en la medida que ambos canales representativos discurren en paralelo, siendo el uno deudor del otro, los 
ámbitos estatutarios determinan en gran medida los correspondientes a los de la representación sindical (Cruz Villalón, 2007: 98).

En segundo lugar, porque la arquitectura institucional prevista en la LOLS refuerza esta trabazón, dando por supuesta una coincidencia no sólo funcional sino también espacial, pudiendo afirmar que, aunque todo el modelo se concibe para que las instancias sindicales puedan actuar tanto a nivel de centro como de empresa, las mismas tienden a conformarse a nivel de centro. Y esta es la razón por la cual hemos considerado que no tiene visos de prosperar alguna propuesta sindical que insta a reconocer el nivel empresarial como ámbito exclusivo y excluyente de las instancias sindicales con el objetivo último de favorecer «el reforzamiento de la función sindical, reconocida constitucionalmente pero insuficientemente desarrollada en las normas legales específicas» (Fernández Toxo, 2005, 208).

A juicio de dicha corriente, los derechos de información, consulta y negociación debieran ser reconocidos exclusivamente a los sindicatos quienes delegarían, según conveniencia sindical, esta representación en estructuras y personas pertenecientes o no al ámbito de la empresa en cuestión. De aprobarse esta propuesta se limitaría enormemente el papel de las instancias de base electiva de segundo grado para asumir competencias a este nivel y, a día de hoy, el comité intercentros desarrolla una función unitaria dentro de un sistema articulado y complejo de representación de los intereses de los trabajadores que tiene importantes virtualidades participativas hasta el punto que hemos defendido una modificación legal en el sentido justamente opuesto, esto es, que establezca de manera preceptiva la constitución del comité intercentros y no facultativa como hasta ahora. Somos, aun así, conscientes de que existen argumentos muy solventes en contra de nuestra interpretación:

En primer lugar, porque la laxitud con la que el legislador estableció la fijación del ámbito de actuación de las instancias netamente sindicales, a diferencia de la formalización con la que reguló a las representaciones estatutarias, pretendía favorecer que las instancias sindicales asumieran un mayor protagonismo a nivel de empresa, produciéndose un reparto más racional entre ambas representaciones.

En segundo lugar, porque esta libertad trata de posibilitar la presencia sindical directa en empresas con multiplicidad de centros de pequeñas dimensiones en los que legalmente no pueden existir representantes unitarios (Cruz Villalón, 1986, 246).

Y, una tercera razón, quizá la más importante, cual es que esta distribución espacial racionalizaría el modelo legal y así el centro de trabajo sería el ámbito preferente de actuación de las instancias electivas mientras que la empresa sería el espacio natural para la acción sindical (Ojeda Avilés, 2005). Sentado lo anterior, el modelo legal hace presumir un favorecimiento de la coincidencia no solo por el hecho de que algunas de las facultades reconocidas en el art. 8.2 LOLS a 
las secciones sindicales, especialmente las vinculadas a la negociación, se condicionen a su presencia en los órganos unitarios lo que, en último término, les fuerza a constituirse con un ámbito coincidente al de los comités (Cruz Villalón, 1992, 61) sino porque la LOLS termina por concebir a la representación sindical como una estructura paralela a la representación unitaria, dotada de parecidos ejes organizativos.

De lo antedicho podemos afirmar que el sindicato también encuentra dificultades a la hora de elaborar una respuesta satisfactoria, especialmente en empresas muy dispersas geográficamente (Baylos Grau y López Bulla, 2003) sin que ello obste para que insistamos en la relevancia que tiene la presencia organizada de trabajadores en este espacio, habida cuenta que el mismo es donde, de facto, se toman la mayoría de las decisiones gerenciales y, por tanto, donde más necesaria es esta presencia. Lamentablemente la LOLS también adolece de una notable carencia a este respecto pues aunque la opción de constituir una sección sindical a nivel empresa es siempre posible, la misma se configura, salvo mejora convencional, como una alternativa a la constitución de secciones sindicales en cada centro de trabajo, es decir, si los afiliados a un sindicato en una empresa con varios centros de trabajo optan por una sección sindical de empresa, esta decisión implica que las secciones sindicales en niveles inferiores no se beneficiarán de las facilidades y prerrogativas en dicho ámbito.

Con esta decisión se traza nuevamente una ligazón entre representaciones estatutarias y sindicales pues «si el comité intercentro se compone de miembros de los distintos centros, sin aumentar el número de representantes de la empresa, la solución paralela aquí consiste en impedir, salvo mejora convencional, la existencia de instancias sindicales centrales superpuestas o adicionales» (Roqueta Buj, 2010: 474; Sáez Lara, 1992: 184).

\subsection{Las secciones sindicales de afectación a la totalidad de la empresa}

La única limitación al principio de libertad que tienen los afiliados para constituir la sección sindical en la totalidad de la empresa vendrá determinada por la regulación que, en su caso, hayan establecido los Estatutos Sindicales en relación al ámbito en el que las precitadas secciones desplegarán su actuación, y ya hemos referido que esta libertad se ha visto claramente reforzada con la STS 18 de julio de 2014 en relación al ámbito en el que cabe la designación de un delegado sindical. El tratamiento de los Estatutos Sindicales (Pérez Anaya, 2011) a este respecto es bastante escaso, salvedad hecha de algún texto paccionado en que expresamente se contempla la empresa como ámbito de constitución (Cruz Villalón, 1992, 60), siendo relativamente habitual que se condicione su constitución al previo acuerdo de la mayoría de las secciones de ámbito inferior (por ejemplo, en el CC Fertiberia (BOE 6.8.2018) se reconoce «la Sección Sindical Intercentros de las secciones sindicales a los Sindicatos más representativos en la Empresa, de conformidad con 
lo establecido en la LOLS, con los mismos derechos, garantías y competencias que las secciones sindicales de centro, pero extensivo a nivel de empresa»).

Esta cautela es plenamente coherente con el modelo expuesto, máxime si pensamos que las secciones constituidas a nivel de empresa actúan, en realidad, como una estructura representativa con funciones de coordinación en el tratamiento de las cuestiones de ámbito superior al del centro de trabajo (de forma similar al comité intercentros) pero que, salvo lo que pueda establecer el convenio de aplicación, carecerán de derechos propios sobre la empresa. Es más incluso se ha admitido en base a la libertad de auto-organización del sindicato, que una sección se constituya con un ámbito distinto al de la empresa o el centro, optando por un nivel intermedio - STC 137/1992 - . Al ser, por tanto, decisión de la sección la opción por constituirse en el ámbito que estime conveniente, si se cumplen los requisitos para proceder a la designación del delegado sindical en el ámbito empresarial, la sección sindical tendrá derecho al nombramiento de este representante, aunque no tenga representación legal unitaria en todos los centros de la empresa (STS 3.2.2017, R. o 39/2016).

En lo que hace a su dinámica de funcionamiento, es relativamente habitual que los estatutos disciplinen los criterios de coordinación entre esta sección y las existentes en cada centro, tanto desde un punto de vista orgánico como funcional (competencias, facilidades o prerrogativas) al tiempo que suelen establecer que la iniciativa para su constitución sea a instancia de la federación sindical y no de los afiliados, aunque generalmente se exige su conformidad. Con esta decisión, el sindicato trata de asegurar su control mediante la vinculación de esta sección al órgano de dirección de la federación que corresponda según el ámbito geográfico de implantación en la empresa.

\subsection{Propuestas de reforma: hacia una mayor sindicalización de la representación unitaria en la empresa}

El modelo legal de representación en la empresa se sustenta en la coexistencia, más o menos pacífica, de representantes unitarios y sindicales y aunque ciertamente los primeros son "por tradición, por efectiva operatividad y por privilegio legal» preponderantes (Cuevas López, J. 1982: 81), la eficacia de su actuación se condiciona al apoyo de una estructura sindical externa, en principio, ajena a estos órganos ya que es la participación del sindicato la que da «la savia y el apoyo" a la representación de base unitaria (Sagardoy Bengoechea, 1986: 100). Ahora bien, las disfuncionalidades del actual modelo legal son evidentes, pues de poco sirven los órganos unitarios sin la excitación de los sindicatos (Casas Baamonde y Escudero Rodríguez, 1984: 89), y aunque ya se ha referido que la existencia de un doble canal de representación es un sistema generalmente aceptado e implantado (Biagi, 1985: 97), la particularidad del modelo español es el amplio haz de facultades reconocido a las instancias uni- 
tarias; interpretación que se refuerza si lo comparamos con el previsto para articular la actuación de estas instancias en las Administraciones Públicas.

Desde círculos sindicales (Benito Valenciano, 2012: 255; Baylos Grau y López Bulla, 2003: 227-29) se insta a modificar este diseño funcional en base a la necesidad de "reforzar los vínculos entre el sindicato y la empresa» (Merino Segovia, 2012: 257), proponiendo que sean las secciones sindicales las que asuman de forma exclusiva las atribuciones vinculadas a la negociación colectiva y las relativas a las medidas de conflicto mientras que el espacio natural de las representaciones unitarias quedaría circunscrito a las competencias informativo-consultivas y exclusivamente en el centro de trabajo.

La evidente consolidación de los órganos unitarios como cauce natural para la participación del sindicato en la empresa nos hace compartir que su hipotética «decapitación supondría una erosión en la defensa de los trabajadores. La función reivindicativa de los órganos unitarios está tan asumida en nuestra cultura jurídica que un encauzamiento de esta instancia representativa hacia funciones exclusivamente participativas traería un terremoto social» (Lahera Forteza, 2000, 309) aunque ciertamente se observa una cierta matización en esta postura en (Lahera Forteza, 2010, 34).

El sindicato actúa en las empresas a través de la representación unitaria, de forma que cualquier propuesta que se efectúe en relación a la conveniencia o no de la modificación del marco normativo debe hacerse partiendo de que la referida sindicalización no sólo consolida a los propios órganos unitarios sino que les da mayor solidez (Cruz Villalón, 1992; 64; Prados de Reyes, 1991: 190; Matía Prim, 1996: 223; Lahera Forteza, 2000: 299).

Para tratar de mitigar las disfunciones referidas, se ha propuesto la idea de «cruzar el doble canal de la figura del delegado sindical» es decir, manteniendo los dos canales representativos pero vinculando a los mismos a través de uno o varios delegados sindicales, designados por los afiliados al sindicato entre aquellos miembros de la sección sindical previamente elegidos como representantes unitarios, que serían los competentes para evitar duplicidades y disfunciones, (Luján Alcaraz, 2003: 316). Hay, sin embargo, argumentos muy sólidos que podrían argüirse para defender una reforma normativa dirigida a la atribución en exclusiva de legitimación negocial a las secciones:

En primer lugar, porque la normativa internacional enfatiza en la necesidad de "garantizar que la existencia de representantes electos no se utilice en menoscabo de la posición de los sindicatos interesados o de sus representantes» —art 5 Convenio núm. 135 OIT y 2.4 Recomendación núm. 143-.

En segundo lugar, porque la diferente naturaleza de estas instancias podría justificar la atribución en exclusiva de determinadas funciones a los sindicatos. No está de más recordar que la única conexión constitucional de las representaciones de base electiva se ha vinculado a la genérica previsión contenida en el 
art. 129.2 CE sobre las diversas formas de participación en la empresa siendo, por tanto, de estricta configuración legal su alcance funcional. $\mathrm{O}$, dicho de otro modo, la representación reconocida a las instancias unitarias dimana directamente de la Ley, (Monereo Pérez, 1992: 378) (Garrido Pérez, 1995: 72), pudiendo ser objeto de limitación en esta sede.

A este respecto, autorizadas voces de la doctrina laboral española han defendido, con buen criterio, que la atribución en exclusiva a los sindicatos (Cruz Villalón, 2017: 173) de legitimación negocial en el ámbito empresarial no solo «significaría un correcto desarrollo de los artículos 28.1 y 37.1 de la Constitución» al tiempo que «lograría un mayor equilibrio de poder con el empresario (Casas Baamonde, 2017: 106)» sino que permitiría solucionar buena parte de los actuales problemas derivados del nuevo modelo de negociación colectiva operados por la Ley 3/2012 (Rodríguez Fernández, 2016: 251). Ahora bien, la práctica negocial en relación a los convenios de empresas es pertinaz, y así tomando como fuente la estadística de convenios que desglosa el sujeto firmante de los convenios de empresa constatamos que la mayor parte de ellos siguen siendo suscritos por representantes de naturaleza electiva, como evidencian los tres cuadros adjuntos, el primero respecto a los convenios firmados en 2012 y los dos últimos respecto a los convenios firmados en 2017 y 2018:

\begin{tabular}{|c|c|c|c|c|c|c|c|}
\hline \multicolumn{8}{|c|}{$\begin{array}{l}\text { CONVENIOS DE EMPRESA EN FUNCIÓN DEL SUJETO COLECTIVO QUE LO FIRMÓ } \\
\text { Registrados hasta diciembre de } 2012 \text { con inicio de efectos económicos en } 2012\end{array}$} \\
\hline & \multirow[t]{2}{*}{$\begin{array}{l}\text { TOTAL CONVENIOS } \\
\text { DE EMPRESA }\end{array}$} & \multicolumn{2}{|c|}{$\begin{array}{l}\text { HAN NEGOCIADO COMITÉ } \\
\text { EMPR. O DELEGADOS } \\
\end{array}$} & \multicolumn{2}{|c|}{$\begin{array}{c}\text { HAN NEGOCIADO SECCIONES } \\
\text { SINDICALES }\end{array}$} & \multicolumn{2}{|c|}{ HAN NEGOCIADO OTROS } \\
\hline & & SI & NO & SI & NO & SI & NO \\
\hline Valor absoluto & 1979 & 1864 & 115 & 515 & 1464 & 279 & 1700 \\
\hline En porcentaje & 100 & 94,19 & 5,81 & 26,02 & 73,98 & 14,1 & 85,9 \\
\hline
\end{tabular}

\begin{tabular}{|c|c|c|c|c|c|c|c|}
\hline \multicolumn{8}{|c|}{ CONVENIOS DE EMPRESA EN FUNCIÓN DEL SUJETO COLECTIVO QUE LO FIRMÓ } \\
\hline & \multirow[t]{2}{*}{\begin{tabular}{|c|} 
TOTAL CONVENIOS \\
DE EMPRESA
\end{tabular}} & \multicolumn{2}{|c|}{$\begin{array}{l}\text { HAN NEGOCIADO } \\
\text { EMPR. O DELEGADOS }\end{array}$} & \multicolumn{2}{|c|}{$\begin{array}{l}\text { HAN NEGOCIADO } \\
\text { SINDICALES }\end{array}$} & \multicolumn{2}{|c|}{$\begin{array}{l}\text { HAN NEGOCIADO } \\
\text { OTROS }\end{array}$} \\
\hline & & SI & NO & sI & NO & SI & NO \\
\hline $\begin{array}{c}\text { Valor } \\
\text { absoluto }\end{array}$ & 1443 & 1370 & 73 & 293 & 1150 & 167 & 1276 \\
\hline En porcentaje & 100 & 94,94 & 5,06 & 20,30 & 79,70 & 11,57 & 88,43 \\
\hline
\end{tabular}

\begin{tabular}{|c|c|c|c|c|c|c|c|}
\hline \multicolumn{8}{|c|}{ CONVENIOS DE EMPRESA EN FUNCION DEL SUJETO COLECTIVO QUE LO FIRMO } \\
\hline & \multirow[t]{2}{*}{\begin{tabular}{|c|} 
TOTAL CONVENIOS \\
DE EMPRESA
\end{tabular}} & \multicolumn{2}{|c|}{$\begin{array}{l}\text { HAN NEGOCIADO } \\
\text { EMPR. O DELEGADOS }\end{array}$} & \multicolumn{2}{|c|}{$\begin{array}{l}\text { HAN NEGOCIADO } \\
\text { SINDICALES }\end{array}$} & \multicolumn{2}{|c|}{$\begin{array}{c}\text { HAN NEGOCIADO } \\
\text { OTROS }\end{array}$} \\
\hline & & SI & NO & $\mathrm{sI}$ & NO & SI & NO \\
\hline $\begin{array}{c}\text { Valor } \\
\text { absoluto }\end{array}$ & 1141 & 1078 & 63 & 219 & 922 & 120 & 1021 \\
\hline En porcentaje & 100 & 94,48 & \begin{tabular}{l|l}
5,52 \\
\end{tabular} & 19,19 & 80,81 & 10,52 & 89,48 \\
\hline
\end{tabular}

Fuente: elaboración propia a partir de los datos proporcionados por la Subdirección General de Estadísticas y Análisis Sociolaboral del Ministerio de Trabajo, Migraciones y Seguridad Social. 


\section{Bibliografía citada}

Agut García, Carmen. (1997). El sindicato en la empresa: (secciones y delegados sindicales). Valencia: Tirant lo Blanch.

-(2004). La sección sindical. Albacete: Bomarzo.

Albiol Montesinos, Ignacio. (1990). El sindicato en la empresa. Madrid: Deusto.

Álvarez Cuesta, Henar. (2006). Puntos criticos y alternativas a las elecciones sindicales y a la mayor representatividad. Granada: Comares.

Álvarez de la Rosa, Manuel. (1991). La organización de los sindicatos en los lugares de trabajo (Empresa y Administración Pública). Madrid: Civitas.

Baylos Grau, Antonio. (2010). "Notas sobre libertad sindical y negociación colectiva». Revista de Derecho Social 50: 25-39.

-(201 I). Un debate europeo sobre la negociación colectiva en la empresa. Madrid: Fundación $10^{\circ}$ de mayo.

Baylos Grau, Antonio., y López Bulla, José Luis. (2003). «Sobre el actual modelo de representación». Revista de Derecho Social,

Benavente Torres, Inmaculada (2014). «Las comisiones ad hoc en los períodos de consulta/negociación». Temas Laborales, 124: 121-56.

Benito Valenciano, Rodolfo., ed. (2012.) Un nuevo sindicalismo para el futuro. Reflexiones sobre trabajo y cambio social. Madrid: Fundación $1^{\circ}$ de mayo.

Biagi, Miagi. (1985). Representación de los trabajadores y democracia en la empresa. Madrid: Ministerio de Trabajo y Asuntos Sociales.

Cabeza Pereiro, Jaime. (2004). «Los delegados sindicales». En Manual jurídico de los representantes de los trabajadores, editado por Escudero Rodríguez, R. y Mercader Uguina, J. R. Madrid: La Ley.

Calvo Gallego, Javier. (Et al), ed. (2008). Employee Representatives in an Enlarged Europe. Bruselas: Office for Official Publications of the European Communities.

Casas BaAmonde, María Emilia (1990). "Democracia, representatividad y afiliación sindicales». En Cuestiones actuales de Derecho del Trabajo: estudios of frecidos por los catedráticos españoles de derecho del trabajo al profesor Manuel Alonso Olea, editado por Montoya Melgar, A. Madrid: Ministerio de Trabajo y Seguridad Social.

- (2017). «La necesaria reforma del Título II del Estatuto de los Trabajadores». En Representación y representatividad colectiva en las relaciones laborales, editado por Cruz Villalón, J., Menéndez Calvo, R., y Nogueira Guastaviano, M. Albacete: Bomarzo; UGT.

Casas Baamonde, María Emilia., y Escudero Rodríguez, Rodríguez. (1984). «Representación unitaria y sindical en el sistema español de relaciones laborales». Civitas. Revista Española de Derecho del Trabajo, 1984.

CCOO (201 I). Reforma legal de la negociación colectiva. Real Decreto-ley 7/2011 de medidas urgentes de negociación colectiva. Guía de acción sindical. Madrid: CCOO.

-(2013). Guía sobre la reforma legal de la negociación colectiva. Madrid: CCOO.

Cruz Villalón, Jesús. (1986). "El reconocimiento de la representación y la acción sindicales en la empresa». En Comentarios a la Ley de Libertad Sindical, editado por Rodríguez-Piñero y Bravo Ferrer, M. Madrid: Tecnos.

- I992. La representación de los trabajadores en la empresa y en el grupo: un marco legal insuficiente. Madrid: Trotta; CARL.

—2007. «La actividad sindical en la empresa: viejos y nuevos problemas». En Treinta años de libertad sindical, editado por VALDÉs DAL-RÉ, F. Madrid: Fundación Francisco Largo Caballero. 
-2017. «Una propuesta de revisión de las reglas sobre representación de los trabajadores en la empresa». En Representación y representatividad colectiva en las relaciones laborales, editado por Cruz Villalón, J., Menéndez Calvo, R., y Nogueira Guastaviano, M. Albacete: Bomarzo; UGT.

Elorza Guerrero, Fernando. (2011). «La representación sindical en la empresa: viejos y nuevos problemas». En El ejercicio de los derechos colectivos de los trabajadores en la empresa, editado por Rodríguez Sañudo, F. y Carrizosa Prieto, E. Madrid: Tecnos.

Escudero Rodríguez, Ricardo. (1985). Los sujetos de los convenios de empresa: representantes unitarios y representantes sindicales. Madrid: Ministerio de Trabajo y Seguridad Social.

Fernández Toxo, Ignacio. (2005). «El ET en la actualidad. Reflexiones para una reforma». En 25 años del Estatuto de los Trabajadores (1980-2005), editado por AAVV. Madrid: Fundación Francisco Largo Caballero.

Ferradans Caramés, Carmen. (2015). Representación y libertad sindical. Límites a la libertad sindical negativa, la mayor representación sindical y su necesaria revisión. Madrid: UGT, 2015.

Garate Castro, Javier. (2012). «La nueva regulación de la legitimación (inicial y plena) para negociar convenios colectivos». En La reforma laboral de 2012 en materia de negociación colectiva, editado por Rodríguez Piñero y Bravo-Ferrer, M. y Valdés DAL-RÉ, F. Madrid: La Ley.

García QuiÑones, Juan Carlos. (2013). «Cuestiones jurídicas en torno a la nueva redacción del artículo 87 del Estatuto de los Trabajadores». Madrid: UGT; UCM.

GARrido PÉrez, Eva. (1995). La información en la empresa: análisis jurídico de los poderes de información de los representantes de los trabajadores. Madrid: CES.

Gómez Abelleira, Francisco Javier. (2011). «La reforma de las garantías subjetivas de la negociación colectiva: legitimación negocial y comisiones negociadoras». En La reforma de la negociación colectiva. Real Decreto-Ley 7/2011, de 10 de junio, editado por Garcia-Perrote Escartín, I. y Mercader Uguina, J. R. Valladolid: Lex Nova.

LAhera Forteza, Jesús. (2000). La titularidad de los derechos colectivos de trabajadores y funcionarios. Madrid: CES.

-.(20I0). "El modelo español de representación de los trabajadores en la empresa: funciones y disfunciones». En La representación de los trabajadores en las nuevas organizaciones de empresa, editado por Valdés Dal-Ré, F. y Molero Marañón, M. L. Madrid: Fundación Largo Caballero.

Luján AlCaraz, José. (2003). La acción sindical en la empresa: marco legal y desarrollo convencional. Madrid: CES.

Matía PRIM, Javier. (1996). «Las elecciones en las empresas». En La reforma del Estatuto de Trabajadores, editado por AAVV. Madrid: La Ley.

Merino Segovia, Amparo. (2012). "La reforma de la negociación colectiva en el RDL 3/2012». Revista de Derecho Social 57: 249-62.

Monereo Pérez, José Luis. (1992). Los derechos de información de los representantes de los trabajadores. Madrid: Civitas; Universidad Granada.

Navarro Nieto, Federico. (1993). La representatividad sindical. Madrid: Ministerio de Trabajo y Seguridad Social.

Nieto Rojas, Patricia. (2011). «Estructuras transversales de negociación. Descentralización productiva y nuevos ámbitos negociales». Sevilla: Comunicación al Congreso Europeo de Derecho del Trabajo y la Seguridad Social. 
-2016. Las representaciones de los trabajadores en la empresa. Valladolid: Lex Nova Thomson Reuters.

Ojeda Avilés, Antonio. (1979). «La libertad sindical». Revista Política Social 121.

—2000. "Los convenios de franja sectoriales». Actualidad Laboral III: 78 I-9I.

-2005. "La representación unitaria: "el faux ami"». Revista Ministerio de Trabajo, 2005.

Palomeque López, Manuel Carlos. (2009). El sistema de relaciones sindicales en España: un balance general del marco jurídico y del funcionamiento de la práctica sindical en el sistema social. Madrid: Fundación Alternativas.

Pérez Anaya, Rosa María (2011). La coexistencia de los canales de representación de los trabajadores en la empresa. Madrid: Difusión Jurídica y Temas de Actualidad.

Prados de Reyes, Francisco Javier (1991). «Representación unitaria y representación sindical en la empresa. Evolución de sistemas». Relaciones Laborales, 1991.

Puebla Pinilla, Ana. (2000). La responsabilidad civil del sindicato: un estudio sobre la responsabilidad derivada de la actividad sindical. Madrid: La Ley.

Rodríguez Fernández, María Luz. (2016). Negociación colectiva, igualdad y democracia. Granada: Comares.

Rodríguez SaÑudo, Fermín. (2007). «Negociación colectiva sobre representación y acción sindical en la empresa». Revista Ministerio de Trabajo 68: 137-70.

Rodríguez-Piñero y Bravo Ferrer, Miguel., y Cruz Villalón, Jesús. (1987). «El sindicato en la empresa en la Ley Orgánica de Libertad Sindical». Relaciones Laborales I.

Roqueta Buj, Remedios. 2010. "Art. 8». En Ley orgánica de libertad sindical: comentada y con jurisprudencia, editado por PÉrez de los Cobos, F. Madrid: La Ley.

SÁEz LaRA, Carmen. (1992). Representación y acción sindical en la empresa. Madrid: Ministerio de Trabajo y Asuntos Sociales.

Sala Franco, Tomás. (2010). «Art. 10». En Ley orgánica de libertad sindical: comentada y con jurisprudencia, editado por Pérez de los Cobos, F. Madrid: La Ley.

VALDÉs DAL-RÉ, Fernando. (2004). «La eficacia jurídica de los convenios colectivos». Temas Laborales 76.

—20 I 2. La negociación colectiva entre tradición y renovación. Granada: Comares. 